\title{
Transformation of Goethite to Hematite Nanocrystallines by High Energy Ball Milling
}

\author{
O. M. Lemine \\ Physics Department, College of Sciences, Al Imam Mohammad Ibn Saud Islamic University (IMSIU), P.O. Box 90950, \\ Riyadh 11623, Saudi Arabia
}

Correspondence should be addressed to O. M. Lemine; leminej@yahoo.com

Received 3 June 2014; Accepted 15 July 2014; Published 18 August 2014

Academic Editor: Yong Ding

Copyright (C) 2014 O. M. Lemine. This is an open access article distributed under the Creative Commons Attribution License, which permits unrestricted use, distribution, and reproduction in any medium, provided the original work is properly cited.

$\alpha$ - $\mathrm{Fe}_{2} \mathrm{O}_{3}$ nanocrystallines were prepared by direct transformation via high energy ball milling treatment for $\alpha$-FeOOH powder. Xray diffraction, Rietveld analysis, TEM, and vibrating sample magnetometer (VSM) are used to characterize the samples obtained after several milling times. Phase identification using Rietveld analysis showed that the goethite is transformed to hematite nanocrystalline after 40 hours of milling. HRTEM confirm that the obtained phase is mostly a single-crystal structure. This result suggested that the mechanochemical reaction is an efficient way to prepare some iron oxides nanocrystallines from raw materials which are abundant in the nature. The mechanism of the formation of hematite is discussed in text.

\section{Introduction}

Iron oxides nanocrystalline powders have attracted increasing attention due to their immense technological poten tial [1-4]. Among the magnetic nanoparticles, hematite has attracted great attention due to its unique characteristics, such as superparamagnetism, high saturation fields, and extra anisotropy contributions, which arise from the effects of finite size and large surface area. Such characteristics allow the potential applications of the hematite nanoparticles into many areas such as magnetism, catalysis, electrochemistry, and biotechnology [5-7]. Various methods have been developed for the synthesis of $\mathrm{Fe}_{2} \mathrm{O}_{3}$ nanoparticles such as microwaves [8], sol-gel method [9], forced hydrolysis [10], and hydrothermal reaction [11]. However, this kind of method has several problems, including high levels of complexity, and has environmentally unfriendly conditions, such as high temperature, reagents, or high $\mathrm{pH}$.

High energy ball milling turns to be the mostly used to prepare nanocrystalline of a variety of materials due to its simplicity, being environmentally friendly, low cost, and its ability to produce large volumes necessary for industrial applications. Several groups studied the production of hematite nanocrystallines from other iron oxides such as $\gamma$ - $\mathrm{Fe}_{2} \mathrm{O}_{3}$ [12] and crude $\alpha-\mathrm{Fe}_{2} \mathrm{O}_{3}$ [13]. To the best of our knowledge, there are only few works dedicated to the production of hematite or magnetite nanocrystalline from goethite $(\alpha-$ $\mathrm{FeOOH}$ ) powders, which is by far the most common oxyhydroxide present in soils $[14,15]$. Wang and coworkers obtained hematite nanocrystallines after $90 \mathrm{~h}$ dry milling of goethite with crystallite size of $18 \mathrm{~nm}$ [15].

In this paper, the production of hematite nanocrystallines $\left(\mathrm{Fe}_{2} \mathrm{O}_{3}\right)$ from goethite $(\alpha-\mathrm{FeOOH})$ in shorter time than the one published in the literature is investigated. The obtained nanocrystalline will be characterized by XRD, Rietveld analysis, TEM, and VSM measurements. Also the reaction mechanism will be discussed.

\section{Experimental}

Commercial powder of goethite $(\alpha-\mathrm{FeOOH})$ was used as the starting material. The powder was introduced into a stainless steel vial with stainless steel balls $(12 \mathrm{~mm}$ and $6 \mathrm{~mm}$ in diameter) in a SPEX 8000 mixer mill. Different milling times were considered $(2,5,10$, and $40 \mathrm{~h})$ and the balls to powder mass ratio was fixed to $10: 1$.

Structural characterization was performed using Rigaku Ultima IV high resolution X-ray diffractometer equipped with $\mathrm{Cu}$ - $\mathrm{K} \alpha$ radiation $(\lambda=1.5418 \AA)$. Rietveld analysis was 


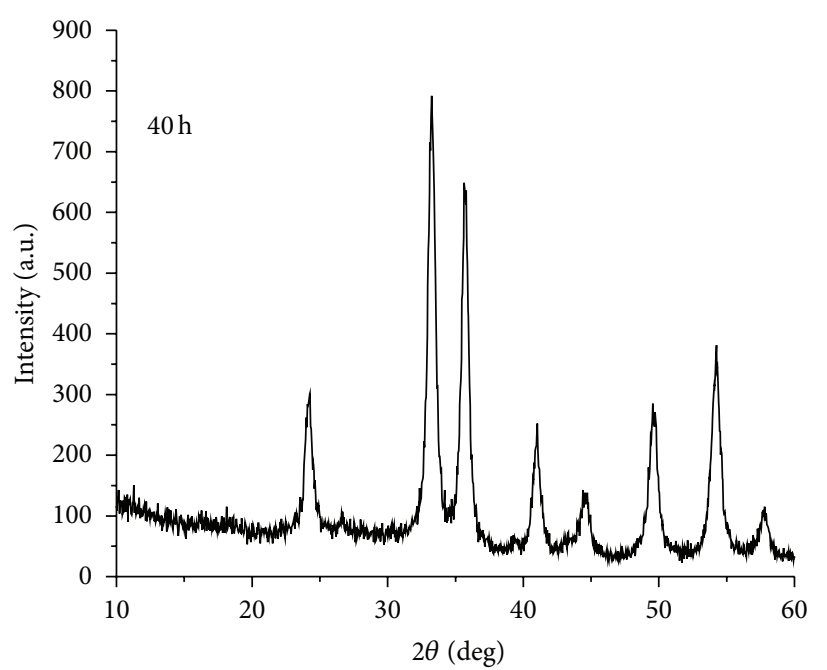

(a)

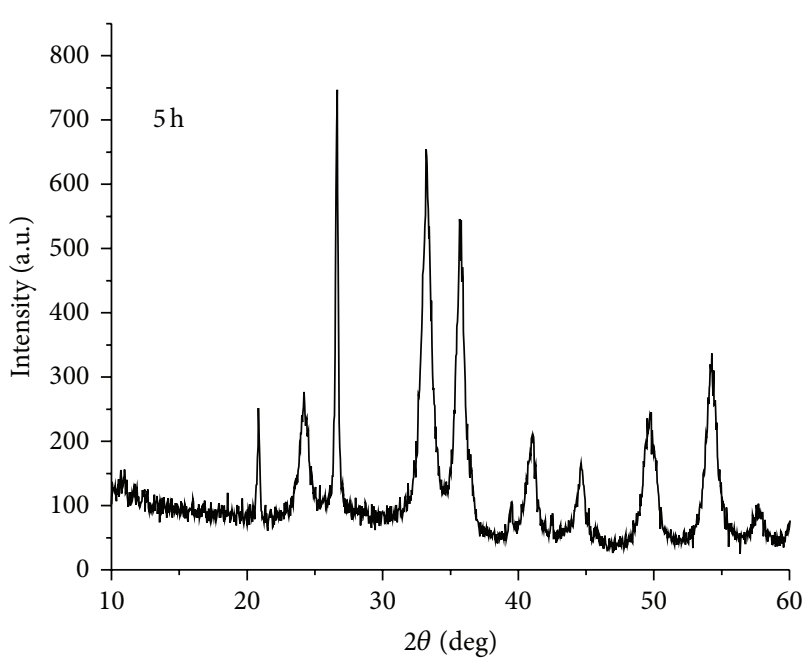

(c)

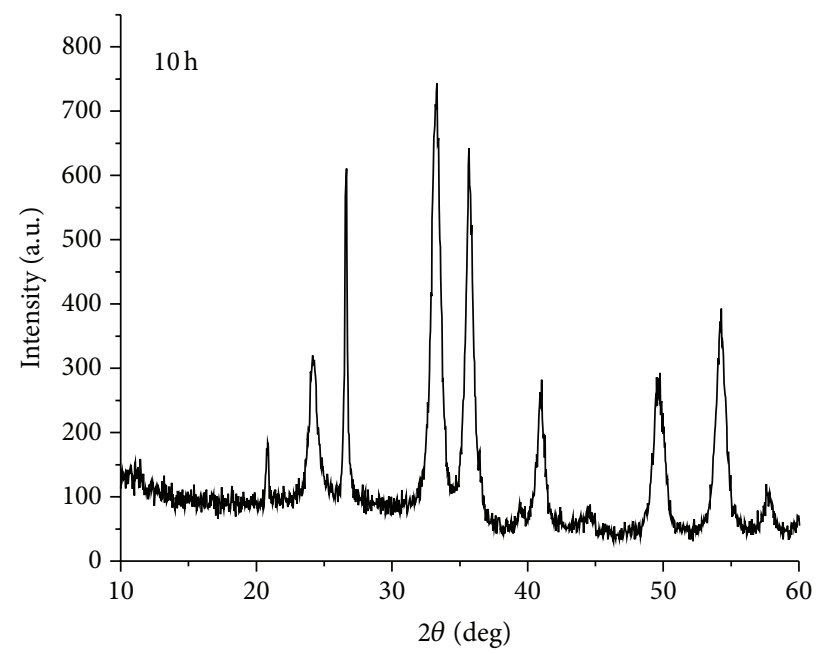

(b)

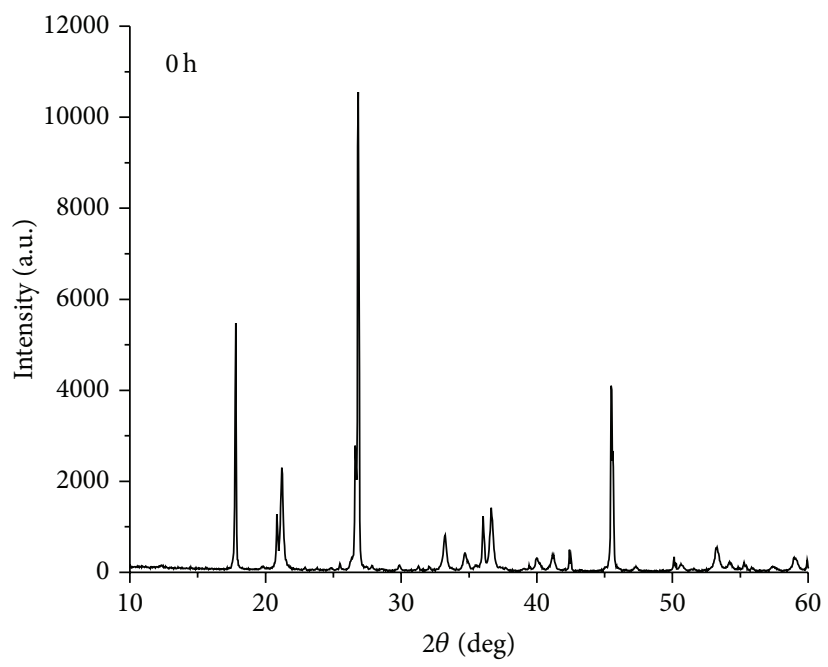

(d)

FIGURE 1: XRD patterns of goethite powder as received and milled for several times.

performed using PDXL program provided with the diffractometer to identify the phases and determine the lattice parameters and the crystallite size. Particles size and shape are determined by transmission electron microscopy (TEM) by using JEOL (JEM-2100F) electron operated at $200 \mathrm{keV}$.

Magnetic measurements were performed at room temperature using a PMC MicroMag 3900 model vibrating sample magnetometer (VSM) equipped with 1 Tesla magnet.

\section{Results and Discussion}

Figure 1 shows XRD patterns for initial powder as received and milled for several milling times. The patterns of unmilled goethite powder show a series of strong and narrow peaks characteristic for high quality crystals. The diffraction peaks become very broad and their relative intensity decreases with increasing milling times. This is mainly due to crystallite size reduction and accumulation of microstrain during mechanical milling. It can be seen that after 40 hours some peaks of the initial powder disappeared and a new peak appeared. This result can be explained by the transformation of goethite under milling to another phase. By comparing the X-ray diffraction patterns of the sample milled for $40 \mathrm{~h}$ and the patterns of $\mathrm{Fe}_{2} \mathrm{O}_{3}$ powders in Figure 2, we can conclude that, after 40 hours of milling, the XRD patterns show reflexions that correspond to an inverse spinel structure, which could be either magnetite $\left(\mathrm{Fe}_{3} \mathrm{O}_{4}\right)$ or hematite $\left(\alpha-\mathrm{Fe}_{2} \mathrm{O}_{3}\right)$; due to their structural similarities, it is difficult to differentiate between both phases from the XRD patterns.

Quantitative phase analyses using the Rietveld method have been performed based on the XRD data to distinguish between the two iron phases. An example of pattern fitting using the sample milled for 40 hours is shown in Figure 3 . Table 1 reports the structural parameters estimated from Rietveld refinements. The estimated crystallite size is in 


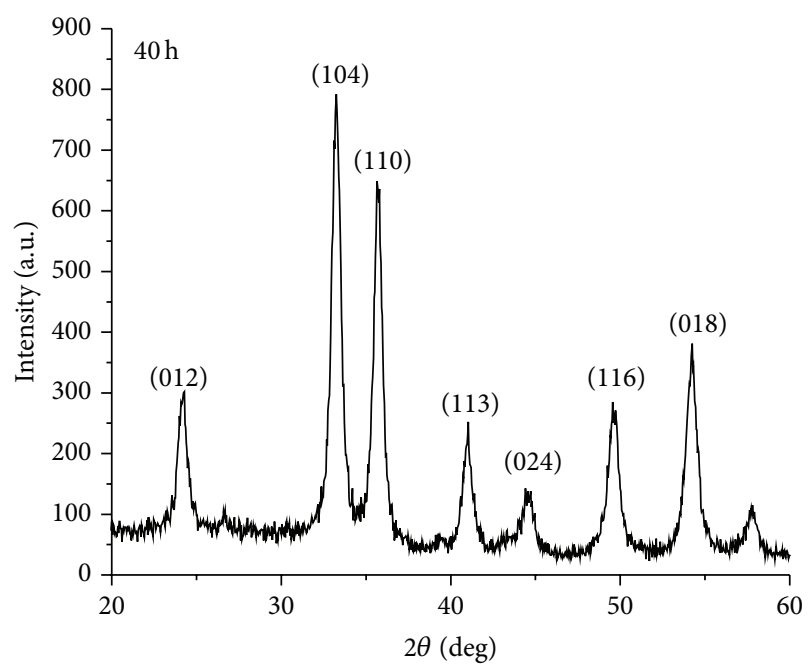

(a)

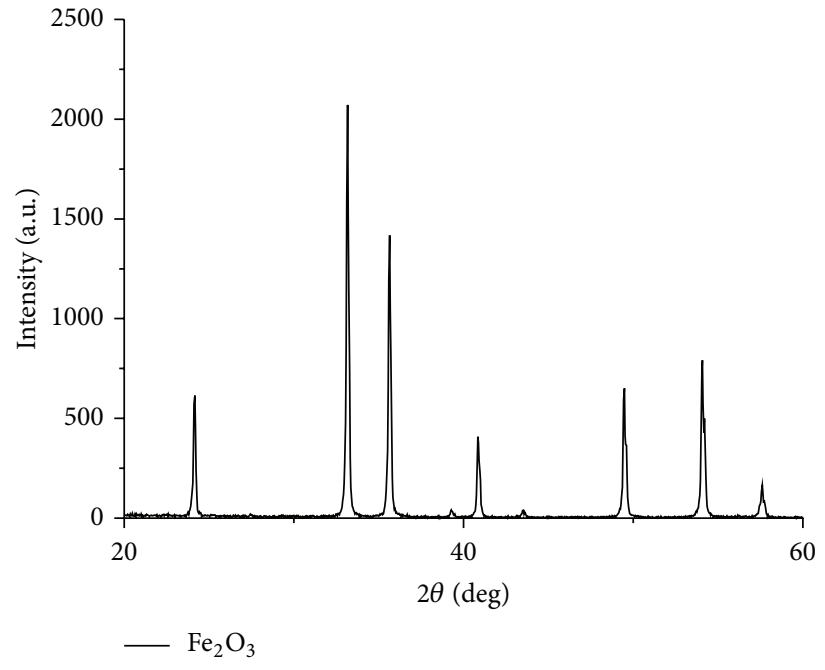

(b)

Figure 2: Comparison between standard $\left(\mathrm{Fe}_{2} \mathrm{O}_{3}\right)$ powder and goethite powder milled for 40 hours.

TABLE 1: Microstructural parameters as obtained from Rietveld refinements.

\begin{tabular}{|c|c|c|c|c|c|c|c|}
\hline $\begin{array}{l}\text { Milling time } \\
t \text { (hours) }\end{array}$ & Phases & $\begin{array}{c}\text { Amount } \\
(\%)\end{array}$ & $\begin{array}{c}\text { Crystallite size } \\
(\mathrm{nm})\end{array}$ & $\begin{array}{c}\text { Strain } \\
(\%)\end{array}$ & & $\begin{array}{l}\text { attice parameters } \\
(\AA)\end{array}$ & \\
\hline \multirow{3}{*}{5} & $\alpha-\mathrm{Fe}_{2} \mathrm{O}_{3}$ & 54 & 8 & 0.330 & $a=5.019(2)$ & $c=13.704$ & \\
\hline & $\varepsilon-\mathrm{Fe}(\mathrm{OH})$ & 33 & 53 & 0.870 & $a=5.039(7)$ & $b=4.452(5)$ & $c=2.933(3)$ \\
\hline & $\mathrm{Fe}$ & 13 & 41 & 0.760 & $a=2.862(1)$ & & \\
\hline \multirow{2}{*}{10} & $\alpha-\mathrm{Fe}_{2} \mathrm{O}_{3}$ & 66.3 & 11 & 0.330 & $a=5.024(1)$ & $c=13.717$ & \\
\hline & $\varepsilon-\mathrm{Fe}(\mathrm{OH})$ & 33.7 & 36 & 0.950 & $a=5.094(5)$ & $b=4.438(3)$ & $c=3.058$ \\
\hline \multirow{2}{*}{40} & $\alpha-\mathrm{Fe}_{2} \mathrm{O}_{3}$ & 87.6 & 10 & 0.140 & $a=5.026(1)$ & $c=13.716$ & \\
\hline & $\mathrm{Fe}$ & 12.4 & 14 & 0.532 & $a=2.873(1)$ & & \\
\hline
\end{tabular}

the nanometer range and decreases with increasing milling time. Phase identification by Rietveld analysis shows the formation of a $\alpha-\mathrm{Fe}_{2} \mathrm{O}_{3}$ nanocrystalline after 5 hours of milling with two other phases, namely, $\varepsilon-\mathrm{Fe}(\mathrm{OH})$ and Fe. For increasing milling time, the percentage of $\alpha-\mathrm{Fe}_{2} \mathrm{O}_{3}$ phase increases and the other phases decrease. Finally, the goethite is transformed to hematite nanocrystalline with a small amount of iron after 40 hours of milling.

This direct transformation of $\alpha$-FeOOH to $\alpha-\mathrm{Fe}_{2} \mathrm{O}_{3}$ due to the mechanochemical effect can be explained according to the following reaction [15]:

$$
\alpha-\mathrm{FeOOH} \longrightarrow \alpha-\mathrm{Fe}_{2} \mathrm{O}_{3}+\mathrm{H}_{2} \mathrm{O}
$$

Wang and Jiang [15] obtained similar results and proposed a mechanism based on the dehydration and transformation of $\alpha$-FeOOH during the ball milling. But the mechanochemical reaction mechanisms remain unclear and more investigation is needed.

TEM and HRTEM image of the milled sample for 40 hours are shown in Figure 3. It can be seen that the crystallite size is the nanometric size which is in agreement with the crystallite size deduced from XRD (Figure 4(a)). The HRTEM image (Figure 4(b)) indicates that the milled sample for 40 hours has a single-crystal structure.

Hysteresis M-H loop measurements performed at room temperature, shown in Figure 5, have been carried out on as received powder as well as milled powder for several times. The values of different magnetic parameters are reported in Table 2. I. It can be seen that the unmilled sample has a paramagnetic behavior. For increasing milling time, the samples exhibit ferromagnetic behavior with weak saturation magnetization value of $6.7 \mathrm{emu} / \mathrm{g}$ for the sample milled at 40 hours. It is important to notice that the magnetic parameters are affected by the milling time, which may be due to different phases obtained during the milling process. For example, Rietveld analysis showed that there are three phases in the sample milled for 10 hours, namely, $\alpha-\mathrm{Fe}_{2} \mathrm{O}_{3}, \varepsilon-\mathrm{Fe}(\mathrm{OH})$, and Fe. For increasing milling time, the phase $\varepsilon$ - $\mathrm{Fe}(\mathrm{OH})$ disappears and the sample is composed mostly of $\alpha-\mathrm{Fe}_{2} \mathrm{O}_{3}$ with small amount of $\mathrm{Fe}$ and that may explain the decrease of the saturation of magnetization. 


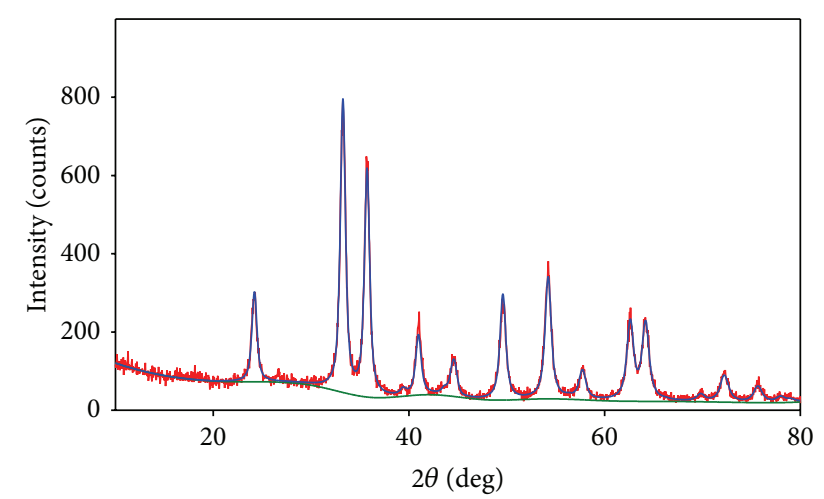

(a)

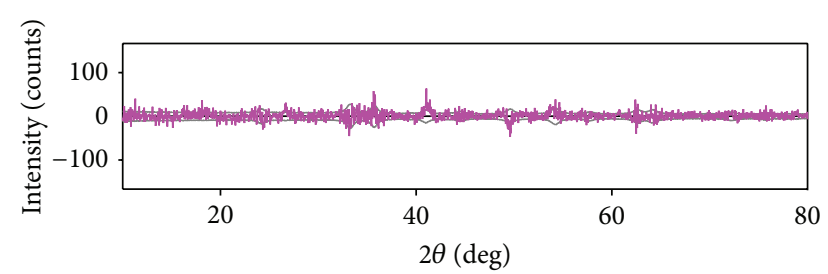

(b)

FIGURE 3: An example of pattern fitting using Rietveld refinements. The net difference between the observed and measured profile is given on bottom of plot.

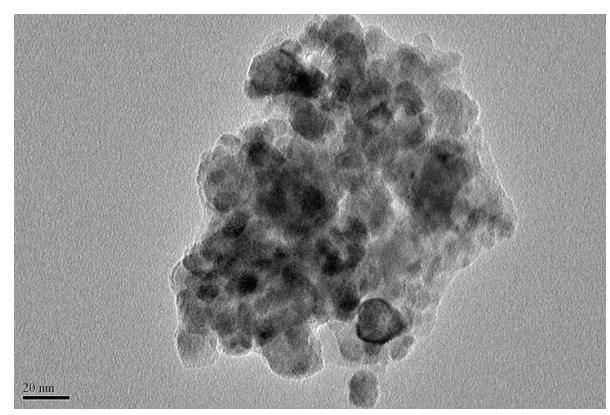

(a)

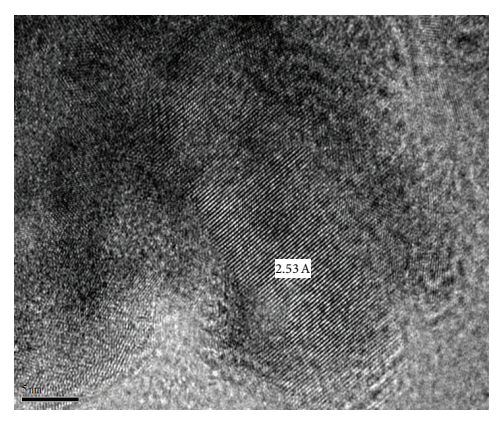

(b)

FIgURE 4: (a) TEM and (b) HRTEM images of sample milled for $40 \mathrm{~h}$.

\section{Conclusion}

$\alpha-\mathrm{Fe}_{2} \mathrm{O}_{3}$ nanocrystalline was successfully prepared by highenergy ball milling of goethite $(\alpha-\mathrm{FeOOH})$ powder after 40 hours of milling. The mechanochemical effect induced by
TABLE 2: Magnetic parameters obtained from VSM measurements.

\begin{tabular}{lcccc}
\hline $\begin{array}{l}\text { Milling time } \\
t \text { (hours) }\end{array}$ & $\begin{array}{c}\text { Magnetic } \\
\text { behavior }\end{array}$ & $\begin{array}{c}\mathrm{Hc} \\
(\mathrm{Oe})\end{array}$ & $\begin{array}{c}\mathrm{Mr} \\
(\mathrm{memu} / \mathrm{g})\end{array}$ & $\begin{array}{c}M \text { or Ms } \\
(\mathrm{emu} / \mathrm{g})\end{array}$ \\
\hline 0 & Paramagnetic & 66.14 & 1.381 & $180.9 \times 10^{-3}$ \\
5 & Ferromagnetic & 49.52 & 289.8 & 8.509 \\
10 & Ferromagnetic & 91.60 & 106.0 & 1.798 \\
40 & Ferromagnetic & 91.66 & 496.8 & 6.715 \\
\hline
\end{tabular}

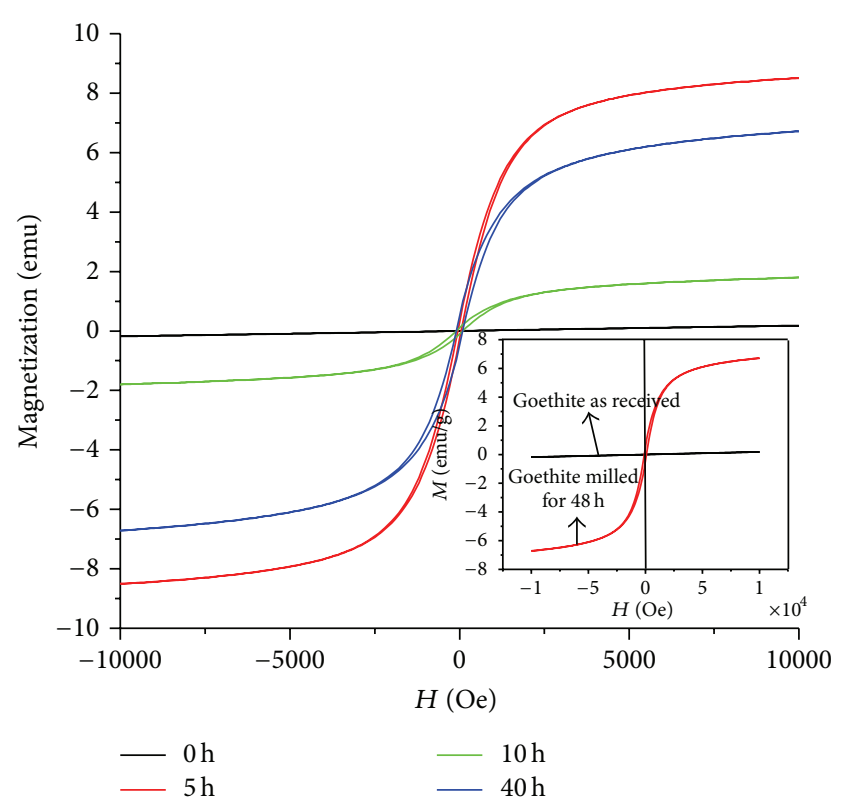

FIGURE 5: Magnetic hysteresis loop of the samples as received and milled for $40 \mathrm{~h}$. The inset shows comparison between the sample as received which is paramagnetic and the one milled for $40 \mathrm{~h}$.

high energy ball milling induced dehydration and transformation of goethite to hematite. This work shows that this method is environmentally friendly and shows easy processes to produce hematite nanocrystalline form goethite which is by far the most common oxyhydroxide present in soils.

\section{Conflict of Interests}

The author declares that there is no conflict of interests regarding the publication of this paper.

\section{Acknowledgment}

The author would like to thank Dr. M. Bououdina for kindly providing support for the Rietveld analysis.

\section{References}

[1] A. K. Boal, V. M. Rotello, Ed., Kluwer Academic, NewYork, NY, USA, 2004.

[2] S. Sun, C. B. Murray, D. Weller, L. Folks, and A. Moser, "Monodisperse FePt nanoparticles and ferromagnetic FePt nanocrystal superlattices," Science, vol. 287, no. 5460, pp. 1989-1992, 2000. 
[3] O. M. Lemine, I. Ghiloufi, M. Bououdina, L. Khezami, M. M'hamed, and A. Taha, "Nanocrystalline Ni doped $\alpha-\mathrm{Fe}_{2} \mathrm{O}_{3}$ for adsorption of metals from aqueous solution," Journal of Alloys and Compounds, vol. 588, pp. 592-595, 2014.

[4] Q. A. Pankhurst, J. Connolly, S. K. Jones, and J. Dobson, "Applications of magnetic nanoparticles in biomedicine," Journal of Physics D: Applied Physics, vol. 36, no. 13, pp. R167-R181, 2003.

[5] N. Mimura, I. Takahara, M. Saitoa, T. Hattorib, K. Ohkuma, and M. Ando, "Dehydrogenation of ethylbenzene over iron oxidebased catalyst in the presence of carbon dioxide," Catalysis Today, vol. 45, no. 1-4, pp. 61-64, 1998.

[6] M. Matsuoka, Y. Nakatani, and H. Ohido, " $\gamma$ - $\mathrm{Fe}_{2} \mathrm{O}_{3}$ ceramic gas sensor," Matsushita National Technical Report, vol. 24, pp. 461473,1978 .

[7] L. Huo, W. Li, L. Lu et al., "Preparation, structure, and properties of three-dimensional ordered $\alpha-\mathrm{Fe}_{2} \mathrm{O}_{3}$ nanoparticulate film," Chemistry of Materials, vol. 12, no. 3, pp. 790-794, 2000.

[8] L. Hu, A. Percheron, D. Chaumont, and C.-H. Brachais, "Microwave-assisted one-step hydrothermal synthesis of pure iron oxide nanoparticles: magnetite, maghemite and hematite," Journal of Sol-Gel Science and Technology, vol. 60, no. 2, pp. 198-205, 1998.

[9] K. Woo and H. J. Lee, "Synthesis and magnetism of hematite and maghemite nanoparticles," Journal of Magnetism and Magnetic Materials, vol. 272-276, Supplement, pp. E1155-E1156, 2004.

[10] J. S. Jiang, X. L. Yang, L. W. Chen, and N. F. Zhou, "A Mössbauer study on the surface hyperfine field of uniform hematite particles," Applied Physics A, vol. 45, no. 3, pp. 245-247, 1988.

[11] X. Wang, X. Chen, X. C. Ma, and H. G. Zheng, "Low-temperature synthesis of $\alpha-\mathrm{Fe}_{2} \mathrm{O}_{3}$ nanoparticles with a closed cage structure," Chemical Physics Letters, vol. 384, p. 391, 2004.

[12] J. S. Lee, C. S. Lee, S. T. Oh, and J. G. Kim, "Phase evolution of $\mathrm{Fe}_{2} \mathrm{O}_{3}$ nanoparticle during high energy ball milling," Scripta Materialia, vol. 44, pp. 2023-2026, 2001.

[13] J. S. Jiang, X. L. Yang, L. Gao, and J. K. Guo, "Nanostructured $\mathrm{CuO}-\alpha-\mathrm{Fe}_{2} \mathrm{O}_{3}$ solid solution obtained by high-energy ball milling," Materials Science and Engineering A, vol. 392, no. 1-2, pp. 179-183, 2005.

[14] G. Gonzalez, A. Sagarzazu, and R. Villalba, "Study of the mechano-chemical transformation of goethite to hematite by TEM and XRD," Materials Research Bulletin, vol. 35, no. 14-15, pp. 2295-2308, 2000.

[15] L.-L. Wang and J.-S. Jiang, "Preparation of $\alpha-\mathrm{Fe}_{2} \mathrm{O}_{3}$ nanoparticles by high-energy ball milling," Physica B: Condensed Matter, vol. 390, no. 1-2, pp. 23-27, 2007. 

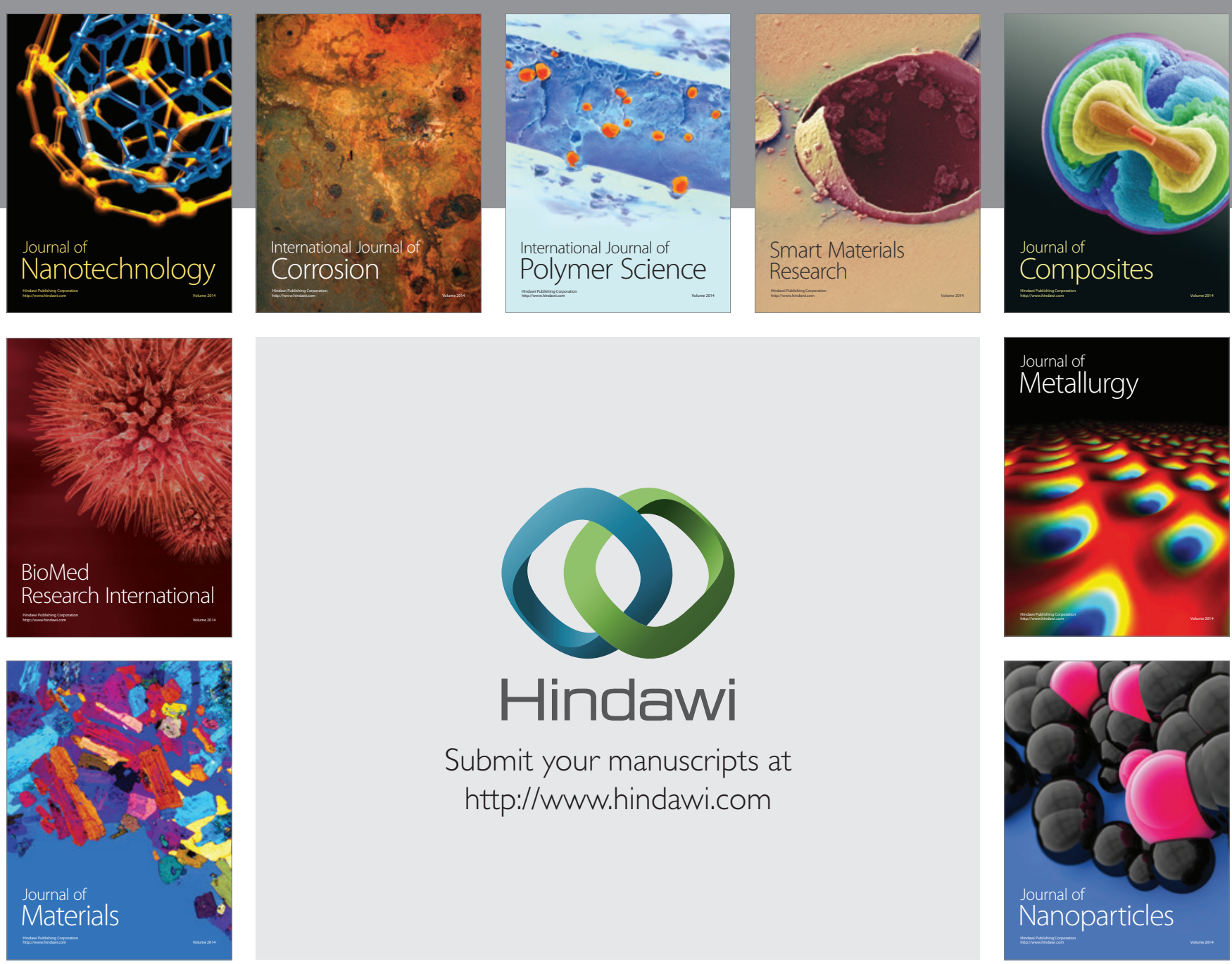

Submit your manuscripts at http://www.hindawi.com
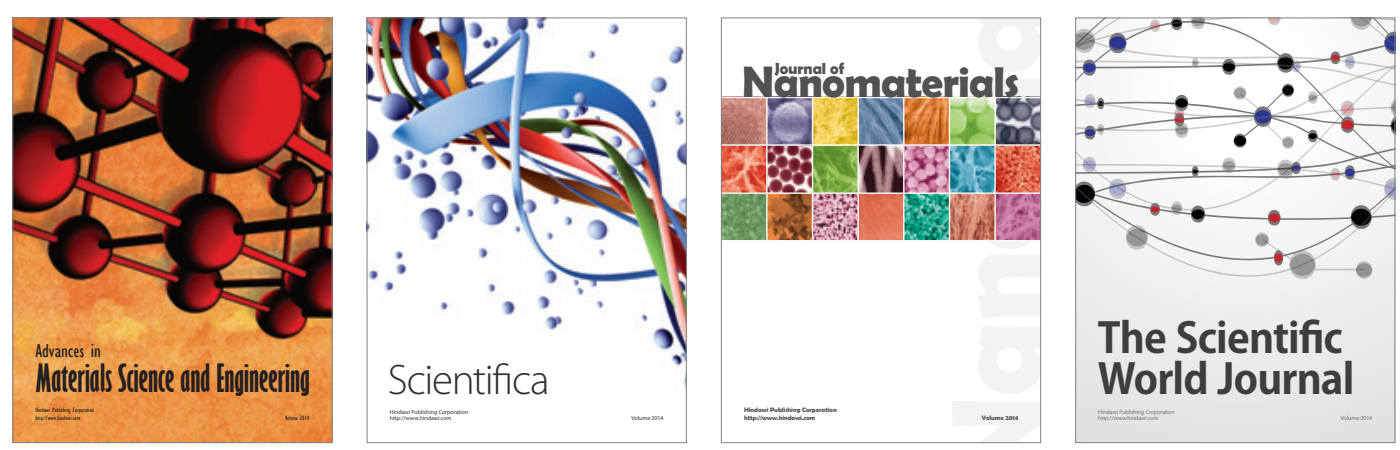

\section{The Scientific World Journal}
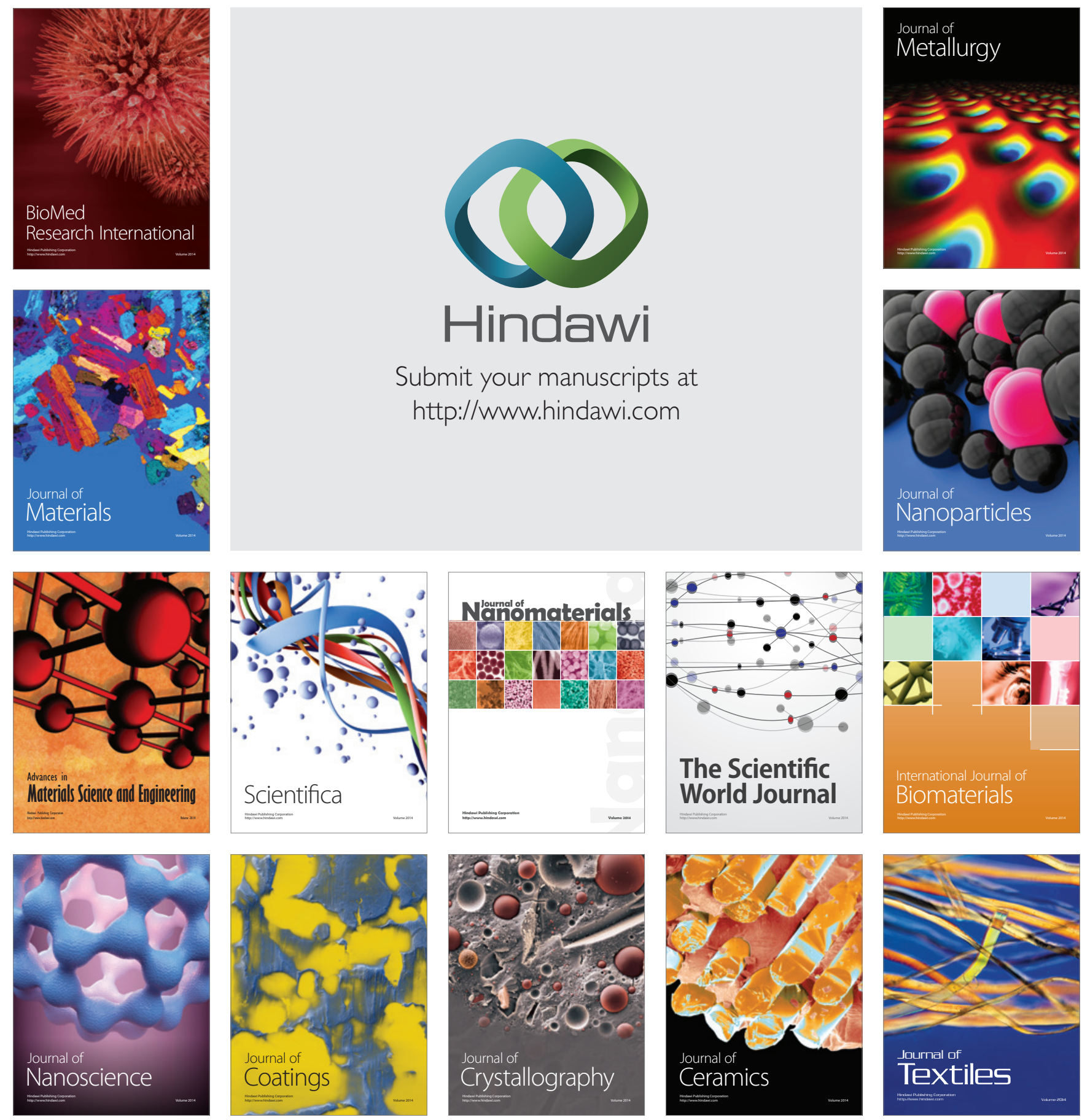